\title{
Transposition
}

Musique et Sciences Sociales

\section{Nina Sun Eidsheim, Katherine Meizel (eds.), The Oxford Handbook of Voice Studies}

New York, Oxford University Press, 2019

Juliana M. Pistorius

\section{CpenEdition}

\section{Journals}

Electronic version

URL: http://journals.openedition.org/transposition/5487

DOI: $10.4000 /$ transposition.5487

ISSN: 2110-6134

Publisher

CRAL - Centre de recherche sur les arts et le langage

\section{Electronic reference}

Juliana M. Pistorius, "Nina Sun Eidsheim, Katherine Meizel (eds.), The Oxford Handbook of Voice

Studies", Transposition [Online], 9 | 2021, Online since 15 December 2020, connection on 23 April 2021

URL: http://journals.openedition.org/transposition/5487 ; DOI: https://doi.org/10.4000/transposition. 5487

This text was automatically generated on 23 April 2021

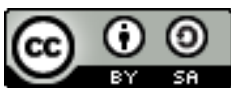

La revue Transposition est mise à disposition selon les termes de la Licence Creative Commons Attribution - Partage dans les Mêmes Conditions 4.0 International. 


\title{
Nina Sun Eidsheim, Katherine
} Meizel (eds.), The Oxford Handbook of Voice Studies

\author{
New York, Oxford University Press, 2019 \\ Juliana M. Pistorius
}

\section{REFERENCES}

Nina Sun Eidsheim, Katherine Meizel (eds.), The Oxford Handbook of Voice Studies, New York, Oxford University Press, 2019, xli +543 p.

1 In a 2015 colloquy published by the Journal of the American Musicological Society, Martha Feldman, Emily Wilbourne, Steven Rings, Brian Kane and James Q. Davies asked, "Why voice now?". ${ }^{1}$ Though not offering a conclusive answer to this provocation, their responses variously pointed at voice's ability to mediate, to multiply, to configure the social, and to trace the borders of the human, as explanations for the timeliness of musicology's "vocal turn". ${ }^{2}$ In the years since, voice studies has kept expanding. So too have the conditions that give rise to its most pressing concerns. The unequal politics of envoicement and the shifting relations between science, ethics and representationespecially where racialised and gendered voices are concerned-are as urgent as ever. Additionally, the recent rise in digitally mediated vocalisation, engendered by the global shift to socially distanced communication, has reignited questions about vocal presence and authenticity.

2 When Feldman et al. composed their colloquy, the discipline of voice studies was still in its infancy. Despite the fact that voice had long been a subject of scholarly concern across the fields of literature, linguistics, psychoanalysis, philosophy, and various hard sciences, the assembly of these interests into a coherent field of study appears to be a comparatively recent phenomenon. It is no coincidence that the first truly interdisciplinary foray into this brave new world, a collected volume published in the 
same year as the JAMS colloquy, concluded its wide-ranging interrogations with the question: what is voice studies? ${ }^{3}$

3 Five years on, voice studies appears to have reached greater certainty about its own academic identity. In The Oxford Handbook of Voice Studies, edited by Nina Sun Eidsheim and Katherine Meizel, the question is no longer, "what is voice studies", but "what is voice?" The order of interrogation may seem counterintuitive: surely the object of study should be defined before the field? But it is testament to the rich diversity, both of the area of inquiry and of this latest edited volume, that the nature of the field itself destabilises the identity of its object.

4 Eidsheim and Meizel take a consciously interdisciplinary approach to the question of what voice is. Introducing their volume with the familiar parable of the blind men and the elephant (here sensibly relieved of its problematic attitude towards disability), the editors argue that definitions of voice are overdetermined by the specific concerns and methods of each discipline's approach to the topic. ${ }^{4}$ Any holistic understanding of voice would therefore require input from a range of scientific and humanistic fields whose epistemological and ontological partialities often seem incompatible. The solution, they suggest, is for scholars of voice to become familiar with fields outside their own, thereby to identify potential blind spots in their individual approaches and to uncover new opportunities for collaborative research across disciplinary boundaries (p. xxvii). The Oxford Handbook of Voice Studies styles itself as a tool towards acquiring such familiarity. In the editors' words, the "overarching intention" of the volume is "to serve as a starting point for new voice studies researchers, or for any voice researcher who is unfamiliar with areas outside her own" (p. xxvii).

Given the enormous range of scholarly domains interested in voice-both as physiological apparatus and as social phenomenon-Eidsheim and Meizel's ambitions for the volume are formidable indeed. For the most part, the editors (alongside a laudably diverse selection of contributing authors) rise to the challenge. With approaches ranging from medicine ${ }^{5}$ to ancient rhetoric, ${ }^{6}$ the twenty-two chapters plus epilogue span the gamut of "measurable", "symbolic", and "material" approaches to voice. $^{7}$

6 The Handbook is divided into six sections, each of which assembles three or four essays from different disciplines. ${ }^{8}$ In the interest of space, I do not provide a separate description of each individual section here. The sub-groupings do not present distinct or unified critical agendas (the editors themselves acknowledge that the combinations are relatively loose and could be imagined differently, p. xxviii), and appear to perform limited epistemological work. What does stand out regarding the structure is a refusal to succumb to a discipline-specific distribution of content: rather than grouping together physiological approaches, for instance, or ethnomusicological or technological approaches, each of the six sections comprises a mix of academic fields, and presents qualitative and quantitative methodologies adjacently. Even at the very basic level or structure, the editors hence invite critical reflection on the possibilities and limitations contained in multifarious approaches to similar questions.

7 At times, these placements give rise to richly provocative contradictions: when Nina Eidsheim's chapter, “Acoustic Slits and Vocal Incongruences in Los Angeles Union Station" (pp. 301-313), excavates the cultural origins of vocal practices immediately after Katarzyna Pisanski and Gregory A. Bryant (in "The Evolution of Voice Perception", pp. 269-300) have described vocal production and perception as products 
of physiological evolution, the critical biases of each approach become blisteringly apparent. Likewise, Jessica A. Schwartz and April L. Brown's contribution, "Challenging Voices: Relistening to Marshallese Histories of the Present" (pp.190-213), not only traces a vocally-mediated politics of coloniality, displacement, and environmental disintegration, it also highlights the limited perspective on political agency offered by the preceding chapter's quantitative analyses of politicians' vocal pitch and volume. ${ }^{9}$

8 Schwartz and Brown's contribution is complemented by Hyun Kyong Hannah Chang's theorisation of the "trans-Pacific modern voice" (pp. 165-189). Writing about the hymn-singing of Korean Christian converts at the turn of the twentieth century, Chang argues for a consideration of vocal practice that expands beyond "tradition" to account also for the influence of colonial expansion and missionary projects in constructing the sound of "the local". ${ }^{10}$ Schwartz, Brown, and Chang's essays may usefully be read in dialogue with Jenny R. Lawy's 2017 critique of vocal empowerment, which destabilises conventional mappings of political agency onto vocal expression. ${ }^{11}$ Like Lawy, Schwartz, Brown and Chang show that "gaining voice" does not necessarily convert to "gaining freedom". These chapters further exemplify one of the volume's strongest features: a commitment to non-Western vocal epistemologies, which also becomes apparent in Robert $\mathrm{O}$. Beahrs's richly evocative contribution on Tyvan throat singing (pp. 315-342) and Alexander K. Khalil's moving rumination on Greek Orthodox yphos (pp. 345-361). Each of these essays destabilises the largely Euro-American frame within which voice studies continues to operate by offering a culturally-situated contemplation of voice as knowing and being in the world. This geographical and cultural diversity is commendable, and one hopes that future collections will build on it by expanding their range to include voices from the so-called "Global South".

9 Several chapters in The Oxford Handbook of Voice Studies challenge the often invisible assumptions that inform voicing and listening in the West. Miriama Young's "Proximity/Infinity: The Mediated Voice in Mobile Music" shows how "pod listening culture" undermines ideals of vocal authenticity by turning the unedited voice into a cipher for the uncanny and the unnatural (pp. 403-418). Shanara R. Reid-Brinkley's powerful interrogation of "black utterance" within the white norms of American college debating (pp. 215-233) and Tom McEnaney's essay on vocal (de-)standardisation on public radio both expose the harmful and discriminatory actions hidden beneath claims to sonic neutrality (pp. 97-123).

Reid-Brinkley and McEnaney's essays demonstrate that vocal convention is political. Standards for vocal behaviour are not merely matters of cultural or individual preference, but instead reflect ideals of national civility and coherence. A similar insight emerges from Eve McPherson's captivating chapter, "Robot Imams! Standardizing, Centralizing, and Debating the Voice of Islam in Millennial Turkey" (pp. 439-455), which traces state-led regulation over the vocal sound of the Islamic call to prayer to reveal how technology, religion, and aesthetics converge in the construction of a unified nation. McPherson's contribution further joins Jennifer Fleeger's chapter on cinematic robots (pp. 419-436) and Cornelia Fales's investigation of "Voiceness in Musical Instruments" (pp. 237-268) to interrogate the cultural expectations and anxieties engendered by voice-like expression beyond the limits of the human.

11 Fales's chapter is one of several that rely extensively on scientific methodologies, including spectral analysis, glottographic measurement, and physiological imaging. ${ }^{12}$ 
These essays offer a useful introduction to the types of experimental techniques available to voice researchers, but rarely demonstrate the integration of such methodologies with critical thinking or philosophical interpretation. An exception is Katherine Meizel and Ronald C. Scherer's contribution (pp. 77-95), which combines Mladen Dolar's psychoanalytical theorisation of vocal presence with spectral analyses of acoustic features to develop a physiologically enhanced understanding of the performativity of vocal identity. Though the qualitative and quantitative sections of the essay do not always interact successfully, Meizel and Scherer begin to demonstrate the possibilities for productive collaboration between scientific and humanistic approaches to voice.

12 The same ideal informs Jody Kreiman's epilogue to the Handbook, titled "Defining and Studying Voice Across Disciplinary Boundaries" (pp.494-513), which proposes a framework for a university-level voice studies curriculum that incorporates philosophy, science, anthropology, communication studies, and psychoanalysis. Kreiman sets out the goals of her curriculum as follows:

1) to provide everyone with enough information to appreciate the unity of the field of study; 2) to provide tools for further forays into unfamiliar research areas; and 3) to help all researchers avoid the mistakes that come from an excessively narrow view of their topic. (p. 501)

13 This description may equally well be read as a manifesto for the volume as a whole, and one could imagine the Handbook being used as a core text in Kreiman's voice studies course. While the full curriculum developed by Kreiman is not published in the Handbook, the volume's companion website (www.oup.com/us/ohovs) should offer further material. At the time of writing this review, a link appears on the companion website, which takes the reader to a website called Keys to Voice Studies. Here, the "Syllabi" section is still "coming soon", but a number of other useful resources, including definitions of important terms and a brief overview of key texts, are available. ${ }^{13}$ The only other material on the Handbook's companion website are two audio examples: the first is a recording of Valeriy Mongush, intended to accompany Beahrs's chapter, while the second is a clip demonstrating the sound of Istanbul's call to prayer as discussed in McPherson's contribution. Fales's chapter on musical instruments directs the reader to the companion website for an expanded version of the text as well as full-colour reproductions of the numerous spectrograms it incorporates; however, this material does not appear on the website. ${ }^{14}$ Currently, the companion website appears to be an idea with great potential, but which still needs to be brought to fruition.

As an educational tool, Eidsheim and Meizel's collection offers a useful introduction to the wide range of possible methodological approaches to voice, and could guide students towards available technologies and experimental practices. From a humanities-based point of view, however, the text's engagement with philosophical orientations needs expansion. The foundational work of theorists such as Jacques Derrida, Adriana Cavarero, Michel Chion and Steven Connor-all of which continues to influence critical voice studies today-appears to be neglected in favour of engagements with "material" and "measurable" manifestations of voice. ${ }^{15}$ Perhaps this bias is intended as a corrective to the 2015 Voice Studies collection mentioned above, which provides a thorough engagement with canonical texts while limiting ethnographic and scientific perspectives. For students and educators alike, Eidsheim and Meizel's Handbook would therefore serve as a valuable companion publication to 
Thomaidis and Macpherson's volume. Taken together, these texts provide a strong basis upon which to construct advanced voice studies programmes.

The Oxford Handbook of Voice Studies is evidently not the last word on voice. If anything, the volume shows how much work is still necessary to construct a field that is truly representative of the myriad forms of voicing with which we constitute our worlds. As an experiment in interdisciplinarity, however, the value of this collection is incontestable. Curating a dialogue between apparently irreconcilable perspectives, Eidsheim and Meizel show how much is to be gained from interacting across and beyond boundaries.

\section{NOTES}

1. FELDMAN Martha (convenor), "Colloquy: Why Voice Now?", Journal of the American Musicological Society, vol. 68, no. 3, 2015, pp. 653-685. DOI: 10.1525/jams.2015.68.3.653.

2. Kane identifies "the vocal turn" as a companion to the "material, speculative, affective, sensory, and ontological turns" in musicology (KANE Brian, "The Model Voice", in FELDMAN, "Why Voice Now?", p. 671).

3. THOMAIDIS Konstantinos, MACPHERSON Ben (eds.), Voice Studies: Critical Approaches to Process, Performance and Experience, New York, Routledge, 2015.

4. The story of the blind men and the elephant is regularly used to argue for interdisciplinarity. In it, three visually impaired men each touch a different part of an elephant. Based on the tactile information they glean, they reach different conclusions about what an elephant is. See, for instance, REPKO Allen F., Interdisciplinary Research: Process and Theory, London, Sage, 2008.

5. SATALOFF Robert T., HAWKSHAW Mary J., "Medical Care of Voice Disorders", pp. 55-75.

6. BUTLER Shane, "What Was the Voice?", pp. 3-17.

7. I adopt these terms from EIDSHEIM Nina Sun, The Race of Sound: Listening, Timbre, and Vocality in African American Music, Durham (NC), Duke University Press, 2019.

8. The sections are: "Part I: Framing Voice: Voice as a Carrier of Meaning"; "Part II: Changing Voice: Voice as Barometer"; "Part III: Active Voice: Voice as Politics"; "Part IV: Sensing Voice: Voice as Multisensory Phenomenon"; "Part V: Producing Voice: Vocal Modalities"; and "Part VI: Negotiating Voice: Voice as Transaction".

9. IIGNORELLo Rosario, "Voice in Charismatic Leadership", pp. 165-189.

10. This work is strongly evocative of Grant Olwage's research on colonial missionary choirs in South Africa. See for instance olWAGE Grant, "Discipline and Choralism: The Birth of Musical Colonialism", RANDALl Annie J. (ed.), Music, Power, and Politics, London, Routledge, 2004, pp. 25-46; and OLWAGE Grant, "The Class and Colour of Tone: An Essay on the Social History of Timbre", Ethnomusicology Forum, vol. 13, no. 2, 2004, pp. 203-226. 11. LAWY Jenny R, "Theorizing Voice: Performativity, Politics, and Listening", Anthropological Theory, vol. 17, no. 2, 2017, pp. 192-215. 
12. See also RADHAKRISHNAN Nandhakumar, SCHERER Ronald C., BANDYOPADHYAY Santanu, "Laryngeal Dynamics of Taan Gestures in Indian Classical Singing", pp. 363-401; SIGNORELLO, "Voice in Charismatic Leadership", pp. 165-189; and SATALOFF, HAWKSHAW, "Medical Care of Voice Disorders", pp. 55-75.

13. See http://keystovoice.cdh.ucla.edu/, accessed on 2 June 2020.

14. Unlike the printed text, the digital version of The Oxford Handbook of Voice Studies does feature full-colour versions of Fales's spectrograms. It does not, however, include the expanded text.

15. EIDSHEIM, The Race of Sound, esp. introduction.

\section{AUTHORS}

\section{JULIANA M. PISTORIUS}

Juliana M. Pistorius is a Leverhulme Early Career Research Fellow at the University of Huddersfield, UK, and Research Fellow at Africa Open Institute, Stellenbosch University, South Africa. She received her doctorate from the University of Oxford in 2018. Her research centres around opera in apartheid and post-apartheid South Africa, and incorporates interests in voice, race, coloniality, and political resistance. She is currently developing a monograph on the operatic projects of visual artist William Kentridge. 